\title{
APPlication OF SPORT SCIENCE ON DEVELOPMENT OF EXERCISE MODEL STROKES BADMINTON BASED ON FOOTWORK
}

\author{
Firmansyah Dlis $^{1)}$, Aridhotul Haqiyah ${ }^{2)}$, Nurul Hidayah ${ }^{3)}$, Dani Nur Riyadi ${ }^{4)}$ \\ 1) Universitas Negeri Jakarta, Indonesia \\ E-mail:fdlis@unj.ac.id \\ 2) Universitas Negeri Jakarta, Indonesia \\ E-mail: aridhotulhaqiyah@yahoo.com \\ 3) Universitas Negeri Jakarta, Indonesia \\ E-mail: $\underline{n l l . h d y @ g m a i l . c o m}$ \\ 4) Universitas Negeri Jakarta, Indonesia \\ E-mail: daninurriyadigundarya@yahoo.com
}

\begin{abstract}
The purpose this study will be useful for developing and implementing a training model design strokes-based footwork. This product was expected to be an alternative model of exercise strokes-based badminton footwork for middle school students aged 12-15. The method used in this study is research and development of ADDIE. This research was conducted at SMP 74 Jakarta within 4 months in May - September 2018 with research steps: (1) Needs Analysis, (2) Model Development Planning, (3) Development of Exercise Model Design, (4) Expert Validation and Model Revision, (5) Evaluation and Revision Test. Based on the data obtained from the results of the study consisting of expert validation, group trials and effectiveness tests, and discussion of the results of the study, it can be concluded as follows: (1) The model of training footwork for beginner's that the researchers have developed obtained 35 items that are worth using, (2) Based on the results of the footwork badminton test, $\mathrm{t}=3,920, \mathrm{db}=58$ and sig. (2-tailed) or $\mathrm{p}$-value $=0,000<0.05$. This means that the training model footwork badminton for beginners is more effective in improving the basic technical skills of badminton footwork.
\end{abstract}

Keywords: Sport Science; Exercise; Strokes Badminton; Footwork

\section{INTRODUCTION}

The development of sports in Indonesia is progressing quite rapidly, where events sport at the local, national and international levels have begun to be encouraged. Events sports have increasingly developed into anticipated social phenomena throughout the world. The sports event is a venue for training, spectacle, education, livelihood and health for the perpetrators. This happens because the government and the community are increasingly aware and understand the importance of sports activities, whether carried out or held for recreational, health, and sports purposes carried out for the purpose of improving achievement. Even as time goes by, knowledge of sports is increasingly developing and widely studied.

Badminton is one of the sports popular with all levels of society. This sport can be played by groups of children to adults, both men, and women. A part from being used as a recreational sport, the role of badminton need not be doubted because it has been able to bring the Indonesian nation to the top of world-class achievements. Evident from various world-level championships, both individuals and teams, Indonesia is able to bring a number of symbols of supremacy in the sport.

Badminton is a sport that uses a tool to compete, a tool called a racket. Comparing a single class played by two people in opposite and double classes played by two opposing pairs. Similar to tennis courts, badminton sports aim to hit the shuttlecock to get over the net so that the shuttlecock falls in the opponent's playing area. Badminton games have now evolved from the old game type to the modern game. This change is influenced by technological advancements that are very concerned about speed and accuracy. If the old type is more pressing on the beauty factor in winning, then the modern type prioritizes how to win in a short time. This impact is influenced by people's 
views on aspects that need to be prioritized to develop optimally in the training process.

Being an accomplished badminton player an athlete must master the basic techniques supporting achievement, including techniques, physical, tactics, and mental skills that must be mastered by every player. The technique is a skill that must be mastered by someone to be able to play one sport. Badminton's basic technique means a skill that must be possessed by someone to be able to play badminton. The basic techniques that must be mastered by a player include blows (strokes). The types of punches that must be mastered are service, underhand, drop shot, smash, netting and drive (PBSI, 2001: 10)

One of the basic techniques of strokes badminton is very important when defensive and offensive. Underhand is punches that can be done by forehand grip or backhand grip, usually done when the player is under a net and a short service line. Because usually this blow is a reply to a drop shot, and punch is underhand also done to restore a thin net punch in order to secure the game back. Often this blow is done lower than the height of the net, sometimes even just a few centimeters from the surface of the field. Underhand is one of the most influential punches when a player is in a position defensive.

While punch strokes, according to Donie (2009: 98) is a punch that is commonly used to press the opponent not to give an opportunity for the opponent to get balls that soar so that the opponent does not get the opportunity to attack with the upper blow. Strokes can also be interpreted as returns or punches that give the ball a relatively flat trajectory, parallel to the floor but beaten high enough over the net.

Badminton is a fast game that requires a very short time to respond to each opponent's return. So from that footsteps or footwork really need to be considered because the delay in returning the opponent's punch is often our failure in returning the opponent's punch with a good and right punch too. With footwork, good a player will be able to move as efficiently as possible to all parts of the field.

Badminton Footwork is an important part of badminton technology, learning and mastering the quick and accurate method is the important link of badminton (Chao Chen, 2014). According to Sapta Kunta Purnama (2010: 27) footsteps or footwork in the game of badminton as a support for the body to move in all directions quickly, so that it can position the body in such a way as to be able to carry out effective punch movements. This technique is the basis for being able to produce a quality punch, of course, if done in a good position, to be able to hit with a good position, an athlete must have a speed of motion. Foot speed cannot be achieved if the footwork is irregular. Herman Subarjah (2013: 20) continues, footwork is a footstep movement that regulates the body to place the position of the body in such a way as to facilitate the movement of hitting the shuttlecock in accordance with its position.

Basically, footwork makes it easy for athletes to carry out various blows either when hitting or returning a punch that comes. This is because the efficiency of the power used when making a punch, where footwork the right will make it easier for shuttlecock to always be in front of the position, making it easier to punch, especially the types of strokes.

Ablow drive is a blow that is carried out from the side hard and flat. This blow can be done with a grip technique forehand or backhand. "The forehand and backhand drives provide a chance to work on foot because they are usually executed between shoulder and knee height to the left or right of center court. Therefore, it emphasizes reaching for the shuttle by shuffling or sliding the feet into position. (Grice, T, 2008: 90)

Blow strokes struck the side of the body and cross the net with a flat trajectory to the opponent. The position of the shuttlecock is close to the left or right side of the bat, the target area is the back of the opponent's field. Punch stroke can be done straight or cross out, punch starts from the upper arm, elbow and wrist, the shuttlecock is stuck in the highest position, knees slightly bent so that the balance when hitting the shuttlecock more awake.

Punch strokes struck with the position of horizontal arms at chest level in front of the body, the position of the feet is well aligned next to each other (with knees slightly bent) or left leg slightly bent forward slightly left, shuttlecock hit with a good strong that position shuttlecock below or above the important shuttlecock over the net.

The Drive is an attacking shot in which the lock is hit by the fast opponent the time has to react. The drive is played from the left and right guidelines, about halfway between the net and the back of the court. The player starts this stroke with a lunge and can be played as a forehand (on the right of the body) and a backhand (on the right of the body). The shuttle travels quickly and flat over the net. (Brahms, 2010: 55)

According to Sapta Kunta (2010: 23), a punch drive is a type of hard and fast punch that has a horizontal direction.blows are Drive usually used to attack or return the ball quickly in a straight line or across the opponent's area, either by using a forehand or backhand. Whereas according to James Poole the punch drive is a hard and flat sideways punch, which is considered an attacking blow. The drive can also be interpreted as a return or blow that directs the ball in a relatively flat track but is hit high enough over the net.

In doing a stroke drive it takes strength to hit the shuttlecock, agility to pursue the direction of the arrival of the shuttlecock, coordination between the footsteps and hand movements and concentration of the eye to the net so that the blow drive is not too high against the net.

In the development of badminton sport training in Indonesia where there are still many trainers who do not provide variations in training, this has a lot of impact on badminton athletes who lack the ability to do punches and know how to do motion techniques without paying attention to the perfect position of foot movements.

According to the results of the observation, the exercise model strokes -based badminton footwork, in this case, is an exercise based on stroke beating based on the rhythm of the direction of the ball without paying attention to patterned strokes so that many players miss steps when returning a punch towards the opponent, but the form of training what 
was applied felt monotonous and less varied according to the researcher. This was felt by researchers to be the cause of boredom for the students due to the lack of attractiveness of the material provided by the trainers. So it is necessary to add and develop a new training model that can hone the skills of techniques strokes -based badminton footwork in the form of punches drive, on badminton players. There are many mistakes so that the ball dies because it cannot be returned perfectly. This is due to dead steps that make the foot position lag to place a punch back.

Footwork is the basic step that really determines the direction of the body where the return of the ball from the opponent is very difficult to predict so it needs special training to make the steps more effective.

Based on the above requirements, the writer is very keen to conduct research to provide an alternative choice by developing strokes -based badminton footwork as an effort to contribute to the development of badminton training in Rawamangun and Middle East Indonesia in general in order to be more accomplished.

\section{METHOD}

The method used in this study is research and development (Research and Development) of ADDIE. In the development of training models Strokes -based Badminton Footwork researchers used the ADDIE model research and development concept which consisted of five steps, namely (1) analysis (2), (2) design (3), (3) development (4) implementation, and (5) evaluation (evaluation).

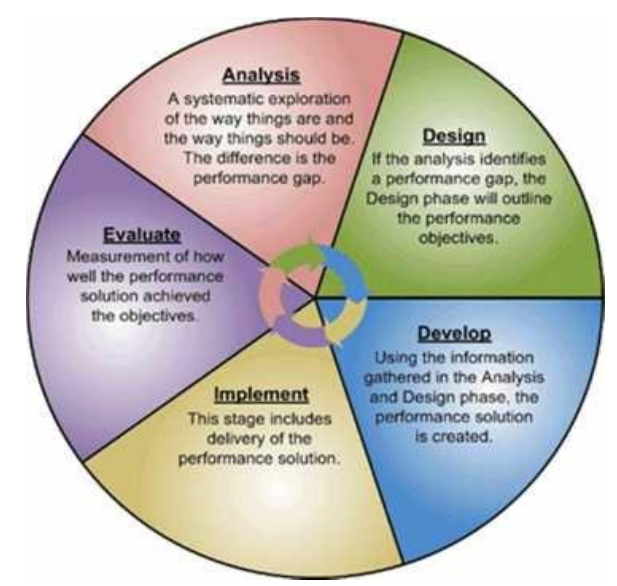

Fig 1. ADDIE Model

Source: (Benny a Pribadi, 2009: 127)

This research was conducted at SMP 74 Jakarta within 4 months in May - September 2018 with research steps: (1) Needs Analysis, (2) Model Development Planning, (3) Development of Exercise Model Design, (4) Expert Validation and Model Revision, (5) Evaluation and Revision Test.

\section{A. Introduction Research}

Conducted preliminary studies using literature studies, studies in the field of data collection, observation and identification process of training the problems found during strokes exercise-based badminton footwork and described and field findings. This is intended to examine training facilities and infrastructure with the aim to find out whether the product to be developed will be used by the subject or not.

In designing the researcher also looks for literature that facilitates the researcher to produce strengths and weaknesses obtained from the writing results and previous research results so that the research is more Yes, with the design that will be developed. The researcher also interviewed the players and trainers to get more accurate input.

The researcher will explore the subject and place of research to get results from the field. The results obtained from the field will be analyzed to obtain conclusions that have been collected. The researcher will analyze and describe several findings, including how the real model of strokes -based badminton footwork will be implemented, then what are the strengths and weaknesses of training model strokes -based badminton footwork this.

\section{B. Model Development Planning}

The next step is to make the initial product in the form of a series of development models that can later be used as guidelines or guidelines to maximize the results of badminton strokes. The initial product is contained in the training model.

The researcher hopes that the product of this training model can be developed in a systematic and systematic manner so that the efficiency and effectiveness of this product are feasible to use. Technique The basic pattern of motion to step in to be able to master all areas of the field must be given a tying technique how to step and take a position so that it is easier to return a blow towards the opponent.

Data analysis in this study used qualitative data analysis and quantitative analysis. Qualitative data obtained from direct observation data that describes the development of children in motion activities. The qualitative data are in the form of presentation. To support qualitative data analysis, quantitative data analysis was also carried out. Quantitative data is data obtained from the score of the test (checklist) in the form of numbers obtained from the children's kinesthetic intelligence observation sheet, and the results of the effectiveness test. So that there will be an overview of the progress that shows the effectiveness of activities that are expected to emerge in early childhood. Quantitative data from observations were analyzed using descriptive statistics, which were presented in percentages and test results data (pre-drops and post-test) basic skills were analyzed by t-test (Kadir, 2015; Memet Muhammad \& A Haqiyah, 2015, 2018). 


\section{RESULT AND DISCUSSION}

The results of the development of an exercise model were footwork beginner's badminton written in the form of a script presented in the forms of exercises footwork badminton. The results are as follows:
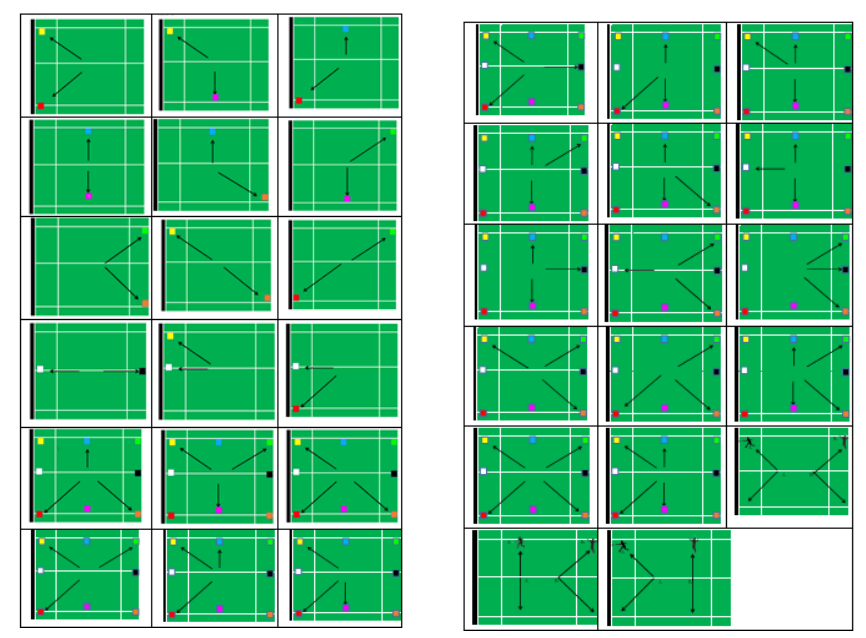

Fig 2. Model of Developed Exercise Patterns (Source: Personal Documents)

\section{A. Results of Analysis}

In this study, there are two general objectives of the results of needs analysis that will be revealed by researchers, namely: (1) training model footwork badminton for eligible beginners used and developed in badminton sport, (2) training model footwork badminton for beginner age is important there is an effective and efficient model variation.

The results of several problems that researchers found in the field through observation and interviews with trainers were in the form of a training model footwork badminton for beginner ages that have been developed

Based on that, the researchers obtained the general purpose of the training model strokes badminton for beginner age. Besides that, the researcher also knows the various characteristics of the research subjects from the training model strokes developed badminton.

\section{B. Feasibility of the Model}

The next step is to conduct an expert test, which aims to obtain validity or feasibility of the model made based on the assessment of the experts. The following are the conclusions from the expert test results summarized in the table below:

Table 2

Conclusions of Experts on Training Models Strokes BadmintonforAthletes Single

\begin{tabular}{cccc}
\hline Name & \multicolumn{2}{c}{ Result } & \\
\cline { 2 - 3 } & Yes & No & Explanation \\
\hline Item Model 1- 35 & $\sqrt{ }$ & - & Feasible \\
\hline
\end{tabular}

Based on these data, the researcher draws the conclusion that that training model footwork badminton for the age of beginners is feasible to use. There are a number of inputs from the three experts that are useful for improving the training model of strokes, badminton including: (1) Directions must be clear so that the child is easily understood, (2) Pictures of exercise patterns must be clearly accompanied by explanations. , this is intended to minimize the occurrence of injury, (4) The exercise model applied must be in accordance with the age characteristics of the athlete, (5) To get good results, the training process must be carried out correctly and clearly.

\section{Model Effectiveness}

After expert evaluation, the training model footwork badminton for beginner age was then revised in the first stage. After product revision, then the model was tested in a group trial with 15 research subjects. Based on expert tests conducted on the training model footwork badminton for beginners, there are 35 items that are worth applying.

Based on the results of expert tests conducted, it can be concluded that: (1) Variations of the exercise must be adjusted and arranged systematically from an easy level to a difficult level, this aims to improve the basic technique footwork athlete's badminton, (2) The trainer should give guidance to children regarding the procedure for doing the training model footwork so that they are not in a hurry to complete their tasks. This is intended so that the desired results are in line with expectations.

\section{Effectiveness Test Results}

The next stage after conducting a small group trial and revised the effectiveness test. Referring to the results of the group trial, the researcher conducted a revision of the initial product to produce 35 items of training models footwork badminton that were tested for effectiveness. After experiencing the second revision stage, the next step is to test the product with 30 research subjects. The table below shows the results of the subject's assessment of the effectiveness of the training model footwork badminton for beginners.

Table 3

Results of Descriptive Statistics Footwork

\begin{tabular}{llrrr}
\hline Group & & N & Mean & $\begin{array}{c}\text { Std. } \\
\text { Deviation }\end{array}$ \\
\hline Footwork & Experiment & 30 & 23.30 & 1.579 \\
& Control & 30 & 21.63 & 1.712 \\
\hline
\end{tabular}

In the table above shows the average ability footwork experimental group at 23.30 and a standard deviation of 1.579 and a control group of 21.63 and a standard deviation of 1.712. This means that descriptively the ability of the experimental group's footwork given the badminton footwork training model was more effective than the control group. 
Table 4

Hypothesis Test Results

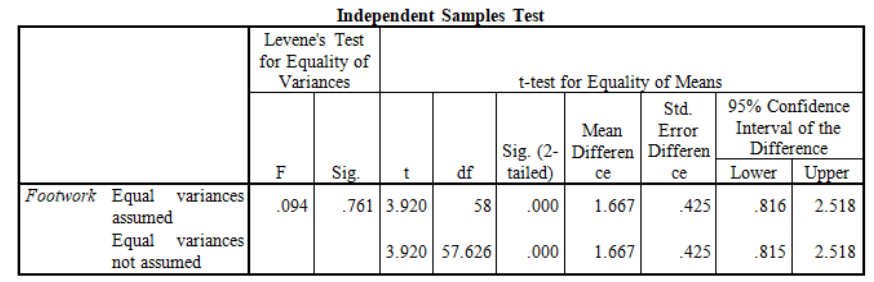

In the table above in column equal variances assumed and Levene's test for equality of variances obtained $\mathrm{F}=$ 0.094 with the sig number. or p-value $0,000=0,761>0,05$, which means the variance of the two groups is equal or homogeneous. Because of the homogeneous variance, the column will be selected equal variances assumed, the $\mathrm{t}=$ $3,920, \mathrm{db}=58$ and sig. (2-tailed) or $\mathrm{p}$-value $=0,000<0.05$ or Ho is rejected. Thus, it was concluded that the model of badminton footwork training was more effective for improving badminton footwork skills for beginner.

\section{E. Discussion of Product Improvement}

Referring to the table of figures obtained above, the researcher concludes that the model of training footwork badminton for beginner age can and is feasible to be applied during training, and is considered effective in improving ability footwork in young children. From the data above there is a difference in numbers that show that there are developments from the initial test and the final test. In the experimental group when the initial test amounted to 624 with an average of 20.30 , then given treatment in the form of training models footwork badminton that have been developed, and then carried out the final test to determine the effectiveness of the model developed and obtained data amounted to 699 with an average 23.30. In the control group when the initial test amounted to 620 with an average of 20.67 with training model treatment the footwork conventional badminton final test results were 649 with an average of 21.63. Thus the training model footwork badminton for beginners is effective for the development of footwork badminton for beginners.

For the sake of achieving product improvements. The following are some of the inputs that will be conveyed by researchers: (1) There need to be adjustments in the application of training models to new children training with footwork in badminton sports, (2) The use of more media/equipment, paying attention to comfort and safety is important, will make the child more maximal in carrying out the training models footwork badminton provided by the trainer, (3) the trainer explains the training model that will be carried out and gives direct practice or an example if there are movements that are felt to be new, (4) always correct every child makes a mistake because correction is one of the hallmarks of technical training, (5) Evaluating after completing training models.

\section{F. Product Discussion}

The model of training footwork badminton for athletes single beginner is intended as a medium of assistance for trainers when delivering material footwork, improving the ability of footwork and also as an additional reference in training. The following are some of the advantages of this product: (1) Improving capabilities footwork badminton in young children, (2) Variations in training can make children more active in doing exercises footwork badminton, (3) This model of training footwork badminton is more effective and efficient, (4) As a reference for trainers in applying the training model footwork for beginners, (5) The training model is presented systematically.

\section{CONCLUSIONS}

Based on the data obtained from the results of the study consisting of expert validation, group trials and effectiveness tests, and discussion of the results of the study, it can be concluded as follows: (1) The model of training footwork beginner's age-old badminton that the researchers have developed obtained 35 items that are worth using, (2) Based on the results of the test the footwork badminton results of the pretest footwork Badminton in the experimental group was 20.80 with a standard deviation of 1.540 and the results of posttest footwork were 23.30 with a standard deviation of 1.579. While the results of pretest footwork in the control group were 20.67 with a standard deviation of 1.348 and the results of posttest footwork were 21.63 with a standard deviation of 1.712 and $\mathrm{t}=3,920, \mathrm{db}=58$ and sig. (2-tailed) or $\mathrm{p}$-value $=0,000<0.05$. This means that the training model footwork badminton for beginners is more effective in improving the basic technical skills of badminton footwork.

\section{ACKNOWLEDGMENT}

This research was supported supported by our colleagues Post Graduate Program, Universitas Negeri Jakarta who provided insight and expertise that greatly assisted the research.

\section{REFERENCES}

Brahms. (2010). Badminton Handbook. UK: Mayer \&Mayer Sport

Chao Chen. (2014). Footwork Teaching of College Badminton Elective Course. $3^{\mathrm{rd}}$ International Conference on Science and Social Research (ICSSR)

Donie. (2009). Pembinaan Bulutangkis Prestasi. Padang: Wineka Media

Grice, T. (2008). Badminton: Step to success. Amerika: Human Kinestetics

Herman Subarjah. (2013). Kepelatihan Pernainan Bulutangkis. Bandung

PBSI. (2001) Pedoman Praktis Bermain Bulutangkis. Jakarta: PBSI

Pribadi, Benny A. (2009). Model Desain sistem Pembelajaran. Jakarta: Dian Rakyat 
Purnama, Sapta Kunta. (2010). Kepelatihan Bulutangkis Modern. Surakarta: Yuma Pustaka

Muhamad, M., \& Haqiyah, A. (2015). Diktat Statistik Pendidikan. FKIP: UNISMA Bekasi.

Muhamad, M., \& Haqiyah, A. (2015). Diktat Statistik Olahraga. FKIP: UNISMA Bekasi. 